duplication and the functional diversification of genes.

In The Origins of Genome Architecture, he advocates using population genetics to understand genomes because the mechanisms involved can explain changes in gene frequency across generations and elucidate genome evolution. For Lynch, population genetics and some non-adaptive mechanisms in particular suffice to understand genomic evolution. He argues that invoking 'mythical macroevolutionary forces' is unnecessary.

Lynch goes a step further by combining molecular mechanisms and evolutionary theory into a coherent evolutionary genomics framework and claiming it as the next phase of evolutionary biology. The ability to straddle both disciplines is rare and hardly attempted in the other direction - few molecular biolo-

gists know much about evolutionary biology. Rightly, Lynch laments this asymmetry.

This book is a must-read for every genome researcher; evolutionary biologists will also profit. It reviews and analyses, competently

Almost every page introduces interesting, unanswered problems - a goldmine for students in search of a thesis topic. Only the most necessary equations interrupt the flow. Almost every page introduces interesting, unanswered problems, making it a goldmine for graduate students in search of a thesis topic. Rarely have I scribbled so many pencil marks in a book's margins.

The last chapter, distinctively entitled "Genomfart" (meaning 'place of passage' or 'the way forward' in Swedish), discusses how much scientific meat lies behind fashionable buzzwords such as complexity, modularity, robustness and evolvability. It alone provides enough intellectual fodder for a stimulating seminar series. Not every evolutionary biologist, genome researcher or 'evo-devo-ist' will agree with Lynch's strong opinions that largely non-adaptive forces shaped genomes, but it is a debate worth having.

As long as we remain unsure what a gene is, we are a long way from understanding genome evolution. That so much is still unknown should not worry us. Rather, it should reassure the next generation of evolutionary genomic biologists that there is much to be discovered.

Axel Meyer is professor of zoology and evolutionary biology in the Department of Biology, University of Konstanz, 78457 Konstanz, Germany. He is co-editor with Yves Van de Peer of Genome Evolution: Gene and Genome Duplications and the Origin of Novel Gene Functions.

\title{
FESTIVAL
}

\section{Neural networking in Manhattan}

\section{Giovanni Frazzetto}

New York city will be criss-crossed this spring by a net of brainy ideas. More than a hundred public events will link neuroscience with art, music and meditation in the city's Brainwave festival, which runs until June.

The metropolitan mix gives the festival its peculiar flavour. Musician Lou Reed introduces and discusses his latest compositions about meditation. Neuroscientist Joseph LeDoux examines sources of fear, and asks how Buddhist practitioners seek to master this emotion, before dashing off to play guitar in his band, The Amygdaloids.

The festival's contemporary art show, Brainwave: Common Senses, opens this month at the cultural centre Exit Art. Cleverly curated, it features images inspired by brain anatomy and function, as well as representations of aspects of consciousness, cognition and memory. The works on show address new technologies of neuroscience and the joint outputs of artists and scientists who have puzzled together over the workings of the brain.

Suzanne Anker extrapolates neurological processes from images of Rorschach tests and brain scans, and renders them into three-dimensional sculptures that are suggestive of bones, sea creatures and body parts. Levels of cognition and perception are represented in a multisensory and interactive installation by artist collective SERU.

Devorah Sperber's apparently random arrangement of 875 spools of coloured thread (pictured) coalesces into a replica of Leonardo Da Vinci's Mona Lisa when observed through a small sphere that mimics the human eye.

All this attention may be symptomatic of the rise of a 'neuroculture', in which neuroscientific understanding becomes part of our daily life. However, some fear that if we gain too much scientific knowledge about how the brain accomplishes creative tasks or causes emotions then it will lead to disenchantment. Brainwave seeks to show that this need not be the case.

Giovanni Frazzetto is a Society in Science Branco Weiss fellow at the London School of Economics, and is at the European Molecular Biology Laboratory.

Brainwave festival events run across New York City until June (www.brainwavenyc.org). Brainwave: Common Senses runs from 16 February to 19 April at Exit Art, New York city (www.exitart.org).

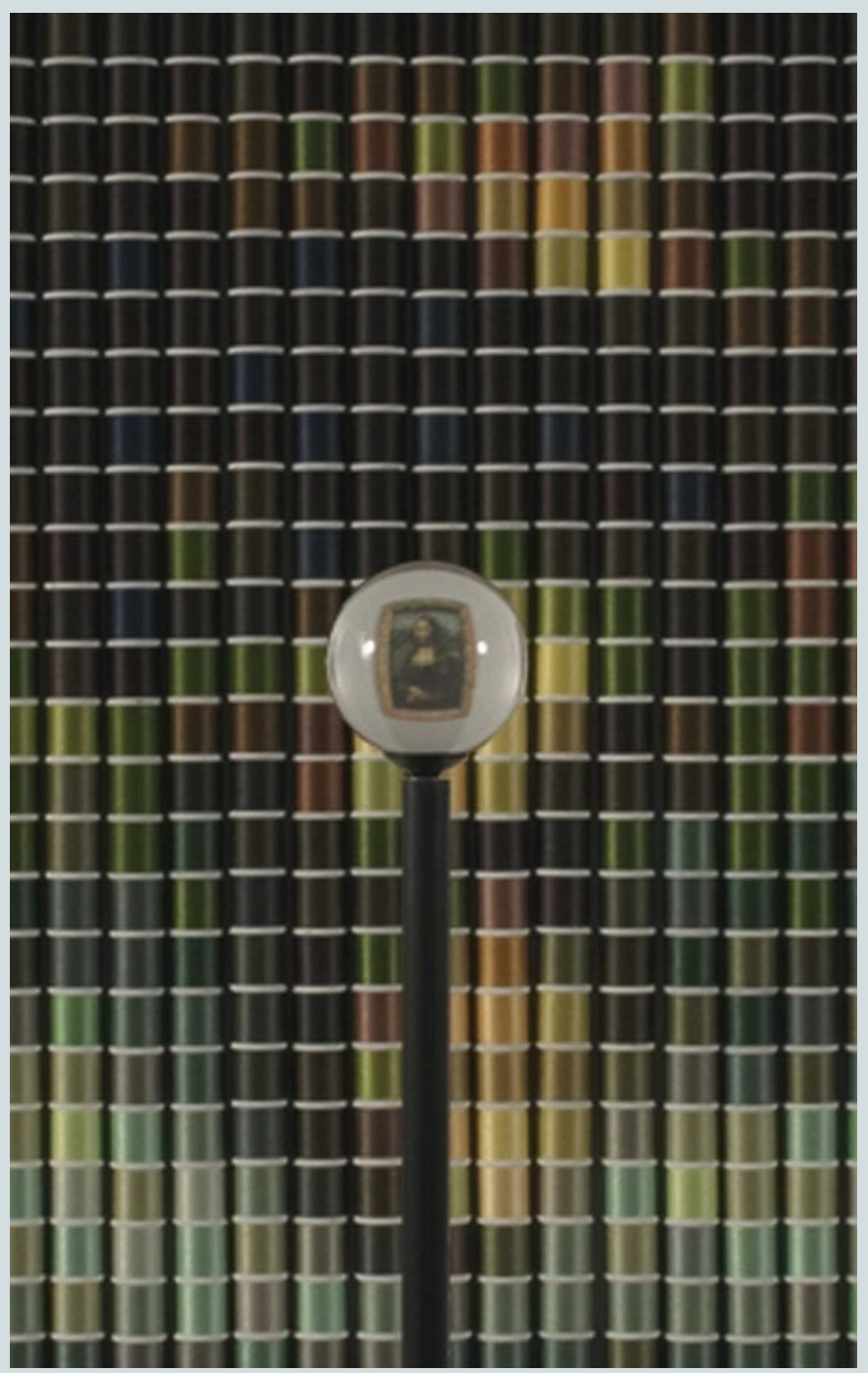

